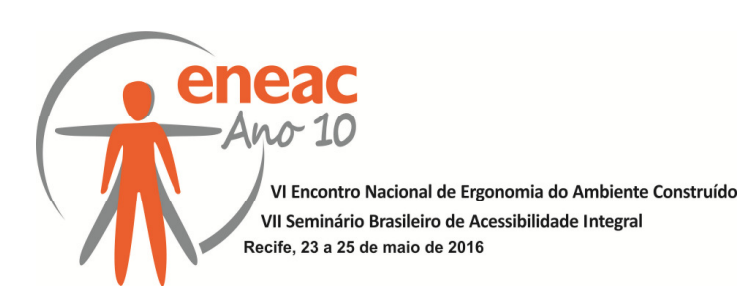

\title{
COMO OS INDIVÍDUOS SE ORIENTAM ESPACIALMENTE?
}

\author{
ANDRADE, Isabela Fernandes; \\ Universidade Federal de Pelotas, Doutoranda em Arquitetura e Urbanismo \\ e-mail: acessiarq@gmail.com
}

\begin{abstract}
RESUMO
O objetivo deste trabalho é apresentar estratégias adotadas pelos indivíduos a fim de orientarem-se espacialmente. Por orientação espacial entende-se a possibilidade do indivíduo situar-se no espaço, acrescida de todos os processos mentais responsáveis pelo seu deslocamento. A metodologia empregada contemplou entrevistas com grupos focais e com funcionários de uma edificação complexa e questionários com usuários, além de pesquisa bibliográfica. Como resultados, desenvolveu-se um quadro-síntese com as formas que podem ser empregadas as placas de sinalização com base na literatura e em normas: direcional, de identificação, informativa, de emergência, de orientação e regulamentadora. Além disso, foi possível criar um quadro com as principais estratégias relacionadas à orientação espacial identificadas.
\end{abstract}

Palavras chave: estratégias de orientação espacial; diferentes indivíduos; ambientes complexos.

\begin{abstract}
This study aims at presenting strategies adopted by individuals in order to orientate in space. It is understood by spatial orientation the possibility of the individual to orientate in space, added to all mental processes responsible by its displacement. The methodology used contemplated interviews in focal groups and with employees of a complex edification and questionnaires with users, besides bibliographic research. As results, it was developed a synthesis-framework with the shapes that can be used the signposts based on the literature and norms: directional, identification, informative, emergency, orientation and regulation. Besides that, it was possible to create a framework with the main strategies related to identified spatial orientation.
\end{abstract}

Keywords: spatial orientation strategies; different individuals; complex environments.

\section{INTRODUÇÃO}

Todas as edificações, principalmente aquelas consideradas complexas - como hospitais, terminais de passageiros rodoviários, portuários e aeroportuários, shoppings, hotéis, escolas, entre outros - devem ser legíveis para que os usuários possam compreender sua configuração espacial e se deslocar com facilidade.

A legibilidade do ambiente e das informações nele disponíveis é extremamente importante para que os indivíduos possam se orientar espacialmente, assim como a habilidade do indivíduo em perceber e tratar cognitivamente essas informações. Deve-se considerar que a percepção de informações do ambiente pode ser influenciada pela pressa, pelo estresse, pelo desconhecimento da edificação e pelas experiências anteriores do indivíduo em relação aos espaços, equipamentos e signos, entre outros. 


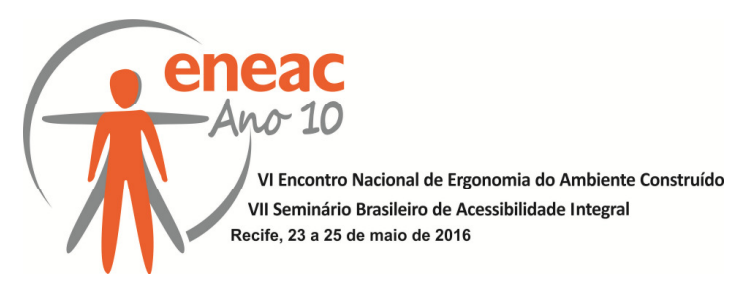

Diversos estudos (Arthur e Passini, 2002; Carpman e Grant, 2002; Lam et. Al., 2003; Ribeiro, 2004; Ribeiro, 2009, entre outros) comprovam que falhas no sistema informacional - que compreende todos os elementos do espaço, seja de arquitetura ou de sinalização -, podem incorrer na desorientação dos indivíduos e, por consequência, em um tempo maior para encontrar o seu destino. Ribeiro (2009) aponta a importância de serem consideradas em projeto questões como a estrutura da informação, a ordem de apresentação, a tarefa a ser realizada, as habilidades do usuário para a elaboração de mapas cognitivos do ambiente e as suas estratégias de navegação.

Logo, é importante que a informação ambiental seja fornecida de diversas formas, tais como adicional - gráfica e de sinalização -, sonora, tátil - piso, mapas fixos e mapas de mão -, luminosa e oral, facilitando a percepção da diversidade de usuários.

De acordo com Assunção José e Coelho (1995), "Entende-se por Orientação Espacial a capacidade que o indivíduo tem de situar-se e orientar-se, em relação aos objetos, as pessoas e o seu próprio corpo em um determinado espaço". Passini (1984) indica que a orientação espacial pode ser definida como um processo cognitivo que envolve duas habilidades do indivíduo: se situar em um ambiente e conseguir representá-lo a partir de um mapa mental (Spatial Orientation) e se locomover ao longo de um percurso e realizar os processos mentais envolvidos nessa tarefa (Wayfinding).

Bins Ely et al. (2001) conclui que, apesar destas duas noções serem distintas, elas se complementam a medida que dependem das informações contidas no ambiente e da habilidade do indivíduo em perceber essas informações e tratá-las cognitivamente pois, mesmo quando o indivíduo está se deslocando (wayfinding), ele faz o processo de compreender, a cada momento, onde ele está (spatial orientation) - a partir de mapas cognitivos.

Para fins deste trabalho, entende-se por orientação espacial a possibilidade do indivíduo situarse no espaço, acrescida de todos os processos mentais responsáveis pelo seu deslocamento.

É importante salientar que a orientação de qualquer pessoa no espaço, seja aberto ou fechado, depende das condições por ele oferecidas. As dificuldades enfrentadas pelos diferentes indivíduos - sejam eles deficientes ou não - são aparentes quando os sistemas informacionais disponíveis em um ambiente não consideram suas estratégias para nele se orientarem. Isto exposto, este trabalho tem como objetivo apresentar estratégias adotadas por diferentes indivíduos a fim de orientarem-se espacialmente.

\section{METODOLOGIA}

Para descobrir as estratégias adotadas por diferentes indivíduos para orientarem-se espacialmente, foram realizadas entrevistas com grupos focais, questionários com usuários e entrevistas com funcionários de uma edificação considerada complexa, além de uma ampla revisão de literatura a respeito do tema.

\section{RESULTADOS}

A revisão de literatura possibilitou reconhecer os diversos fins empregados para as placas de sinalização: direcional, de identificação, informativa, de emergência, de orientação e regulamentadora. A partir disso, e com base em diferentes autores e normas técnicas - Carpman e Grant (2012), NBR-9050 (2015), NBR-9070 (2001), NBR-13434-1 (2004), NBR-13434-2 (2004), Gibson (2009) e Berger (2009) -, elaborou-se um quadro-síntese com os principais tipos de sinalização (quadro 1). Na primeira coluna, apresentam-se os tipos de sinalização identificados, bem como os autores que os definiram. Na segunda coluna está exposta a descrição de cada tipo de sinalização. A terceira e última coluna ilustra, a partir de uma imagem, a sinalização empregada. 


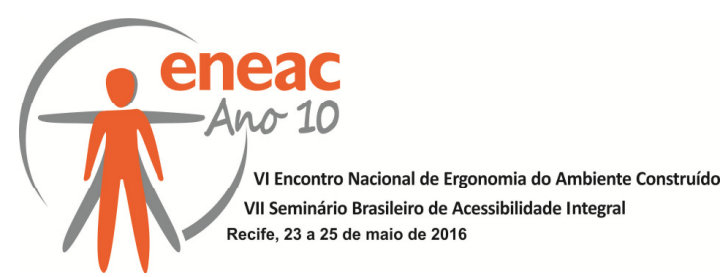

Quadro 1: Tipos de Sinalização sob o ponto de vista de diferentes autores.

\begin{tabular}{|c|c|c|}
\hline TIPOS DE SINALIZAÇÃO & DESCRIÇÃO & ILUSTRAÇÃO \\
\hline $\begin{array}{c}\text { SINALIZAÇÃO } \\
\text { DIRECIONAL } \\
\text { CARPMAN E GRANT (2012), ABNT NBR 9050 } \\
\text { (2015), GIBSON (2009), BERGER (2009) }\end{array}$ & $\begin{array}{l}\text { Sinalização direcional internas e externas indicam como } \\
\text { proceder para chegar a determinado destino: siga em frente, } \\
\text { vire à direita, por exemplo. Geralmente se localizam em pontos } \\
\text { de tomada de decisão, onde se tem mais de uma opção de } \\
\text { caminho a percorrer. Podem ser usadas de três formas: visual - } \\
\text { associa setas de direção a textos -, tátil - adota recursos como } \\
\text { guia de balizamento ou piso tátil - e sonora - insere recursos de } \\
\text { áudio para explanação de direcionamentos. }\end{array}$ & tes/defaultfiles/00-eureka-carpark- \\
\hline $\begin{array}{l}\text { SINALIZAÇÃO DE } \\
\text { IDENTIFICAÇÃO } \\
\text { CARPMAN E GRANT (2012), ABNT NBR 9050 } \\
\text { (2015), GIBSON (2009), BERGER (2009) }\end{array}$ & $\begin{array}{l}\text { Sinalização de identificação indicam onde você está. } \\
\text { Podem ser utilizadas em ambientes externos e internos, bem } \\
\text { como em mobiliários. Associadas aos ambientes, indicam } \\
\text { nome, número ou outro rótulo de determinado local. Já quando } \\
\text { relacionadas aos mobiliários pode ser usada para identificar } \\
\text { comandos. São capazes, ainda, de confirmar que você } \\
\text { alcançou o destino almejado. }\end{array}$ & http://pinterest.com/pin/328973947751791781/ \\
\hline $\begin{array}{l}\text { SINALIZAÇÃO } \\
\text { INFORMATIVA } \\
\text { CARPMAN E GRANT (2012) }\end{array}$ & $\begin{array}{l}\text { Sinalização informativa traz orientações pormenorizadas } \\
\text { sobre como encontrar o seu caminho. São utilizadas tanto } \\
\text { em ambientes internos como externos e indicam distâncias, } \\
\text { direções (em palavras) e destinos. Por exemplo, uma placa de } \\
\text { aviso pode usar a frase "Sempre em frente, depois à esquerda" } \\
\text { ou "Para o } 1^{\circ} \text { pavimento, pegue o elevador" para indicar o seu } \\
\text { percurso, em vez de usar mensagens e sinais taquigráficos } \\
\text { como uma placa direcional faria. }\end{array}$ & $\begin{array}{l}\text { To exit at the General Hooker } \\
\text { Entrance, follow signs to } \\
\text { Elevators } 182 \text {, take those } \\
\text { elevators to Floor } 1 \text { and follow } \\
\text { slgns. } \\
\text { CARPMAN \& GRANT. Directional Sense: How to Find } \\
\text { Your Way Around. 2012. p.185. }\end{array}$ \\
\hline $\begin{array}{l}\text { SINALIZAÇÃO DE } \\
\text { EMERGÊNCIA } \\
\text { ABNT NBR } 9050 \text { (2015), ABNT NBR } 9077 \\
\text { (2001), ABNT NBR 13434-1 e 13434-2 (2004) }\end{array}$ & $\begin{array}{l}\text { Sinalização de emergência é utilizada para indicar rotas de } \\
\text { fuga e saídas de emergência. São utilizadas, em geral, no } \\
\text { interior de edificações. Podem ser adotadas para indicar uma } \\
\text { situação de perigo (NBR 13434). }\end{array}$ & $\begin{array}{l}\text { https://upload.wikimedia.org/wikipedia/commons/ } \\
\text { 8/80/Glass_exit_sign.jpg - acesso em } 12.02 .2016\end{array}$ \\
\hline $\begin{array}{l}\text { SINALIZAÇÃO DE } \\
\text { ORIENTAÇÃO } \\
\text { GIBSON (2009), BERGER (2009) }\end{array}$ & $\begin{array}{l}\text { Sinalização de orientação é adotada para oferecer aos } \\
\text { visitantes uma visão geral do local e seus arredores. São } \\
\text { tratadas na forma de mapas abrangentes. Esse tipo de } \\
\text { sinalização deve estar associada com sinalizações dos tipos } \\
\text { direcional e de identificação. Segundo Berger (2009, p. } 77) \text {, } \\
\text { terminais aeroportuários e rodoviários normalmente requerem } \\
\text { um mapa que destaque funções principais, incluindo } \\
\text { informações essenciais como sala de espera e embarque. }\end{array}$ & www.fhwa.dot.gov - acesso em 12.02.2016 \\
\hline $\begin{array}{l}\text { SINALIZAÇÃO } \\
\text { REGULAMENTADORA } \\
\text { GIBSON, 2009), BERGER (2009) }\end{array}$ & $\begin{array}{l}\text { Sinalização regulamentadora ajuda a descrever o que pode } \\
\text { ou não fazer em determinado local. Pode transmitir uma } \\
\text { mensagem simples, como "Não fume" e "Perigo", ou ser } \\
\text { complexa, indicando como os cidadãos devem apreciar e } \\
\text { utilizar um parque público. }\end{array}$ & $\begin{array}{l}\text { SWIMHING } \\
\text { IN THIS } \\
\text { AREA }\end{array}$ \\
\hline
\end{tabular}

Fonte: Andrade (2016), a partir de Carpman e Grant (2012), NBR-9050 (2015), NBR-9070 (2001), NBR-13434-1 (2004), NBR-13434-2 (2004), Gibson (2009) e Berger (2009).

Foi possível, ainda, elaborar um quadro com as principais estratégias identificadas à luz da literatura e da metodologia aplicada. Neste quadro, a sinalização - considerada uma das formas de informação adicional - foi ampliada de seis - conforme quadro 1 - para oito itens: direcional, de identificação, de identificação tátil, informativa, de emergência, de orientação (mapa fixo), de orientação (mapa de mão) e regulamentadora. 


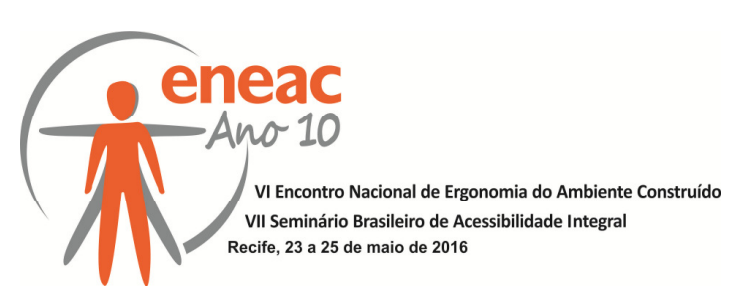

Além disso, podem-se destacar estratégias não identificadas na literatura e/ou em normas como, por exemplo, o caso de uma pessoa cega que identificou o acesso à edificação a partir da troca de temperatura entre ambiente interno (ar condicionado) e ambiente externo.

\section{CONSIDERAÇÕES FINAIS}

A partir do reconhecimento das estratégias adotadas por diferentes usuários para orientarem-se espacialmente, pode-se ratificar a importância de se transmitir a mesma informação de diferentes formas a fim de atingir a maior parte dos indivíduos.

Além disso, as experiências anteriores, seja em relação a edificações semelhantes (de mesmo uso) ou, até mesmo, a outros edifícios reconhecidamente complexos, podem auxiliar a leitura e a compreensão espacial.

Constatou-se, na aplicação dos métodos - entrevistas com grupos focais de diferentes indivíduos (seis grupos), entrevistas com funcionários de determinada edificação complexa e questionários com usuários desta mesma edificação - que as estratégias mais empregadas são a sinalização (principalmente direcional e de identificação) e a informação oral. Algumas pessoas destacaram, ainda, se orientarem a partir das atividades humanas (aglomeração de pessoas em determinado local) a fim de identificar, por exemplo, atividades como a venda de bilhetes em terminais de passageiros.

Uma crítica extraída das entrevistas com grupos focais, considerada bastante relevante, está relacionada às placas direcionais que, normalmente, indicam o caminho, mas raramente, transmitem ao leitor as distâncias a serem percorridas e o tempo que levará para atingir o seu destino.

\section{REFERÊNCIAS BIBLIOGRÁFICAS}

ANDRADE, Isabela Fernandes. Estratégias de orientação espacial adotadas por diferentes indivíduos no uso de terminais aeroportuários. Tese apresentada ao Programa de PósGraduação em Arquitetura e Urbanismo da Universidade Federal de Santa Catarina, como um dos requisitos para obtenção do título de Doutor em Arquitetura e Urbanismo, sob orientação de Vera Helena Moro Bins Ely. (no prelo - 2016)

ASSUNÇÃO JOSÉ, Elisabete da; COELHO, Maria Teresa. Problemas de Aprendizagem. 6⿳亠丷厂 ed. São Paulo: Ática, 1995.

BINS ELY, Vera Helena Moro; DISCHINGER, Marta; DAUFENBACH, Karine; RAMOS, Juliana de Lima; CAVALCANTI, Patricia Biasi. Desenho Universal - por uma arquitetura inclusiva. Grupo PET/Arq/SESu. Departamento de Arquitetura e Urbanismo. UFSC: 2001.

PASSINI, Romedi. Wayfinding in architecture. New Yor: Van Nostrand Reinhold, 1984.

RIBEIRO, Lúcia Gomes. Onde estou? Para onde vou? Ergonomia do ambiente construído: wayfinding e aeroportos / Lúcia Gomes Ribeiro; orientadores: Cláudia Renata Mont'Alvão, Respício Antonio do Espírito Santo Jr. Tese (Doutorado em Artes e Design) - Rio de Janeiro: Pontifícia Universidade Católica do Rio de Janeiro, 2009. 